\title{
Experimentally Manipulating the Landscape of Fear to Manage Problem Geese.
}

\begin{tabular}{|c|c|}
\hline Journal: & Journal of Wildlife Management and Wildlife Monographs \\
\hline Manuscript ID & JWM-16-0105.R1 \\
\hline Wiley - Manuscript type: & Research Article \\
\hline Date Submitted by the Author: & 12-Dec-2016 \\
\hline Complete List of Authors: & $\begin{array}{l}\text { Atkins, Alex; Percy FitzPatrick Institute of African Ornithology, Biological } \\
\text { Sciences } \\
\text { Redpath, Steve; University of Aberdeen Institute of Biological and } \\
\text { Environmental Sciences } \\
\text { Little, Robin; FitzPatrick Institute, Biological Sciences } \\
\text { Amar, Arjun; FitzPatrick Institute, DST/NRF Centre of Excellence, Biological } \\
\text { Sciences }\end{array}$ \\
\hline Keywords: & $\begin{array}{l}\text { Alopochen aegyptiaca, Egyptian goose, Cape Town, falconry, nuisance } \\
\text { species, landscape of fear, predation risk, predator-prey dynamics }\end{array}$ \\
\hline Abstract: & $\begin{array}{l}\text { Negative interactions between humans and wildlife are increasing, often } \\
\text { leading to conflict between different stakeholders over appropriate } \\
\text { management interventions; therefore effective and acceptable methods of } \\
\text { pest and nuisance wildlife management are urgently sought. This study } \\
\text { adopts a mechanistic approach, using knowledge of animal behavior, to } \\
\text { develop and apply management tools aimed at solving important } \\
\text { management issues. We experimentally tested whether introducing trained } \\
\text { Harris's hawks Parabuteo unicinctus (through falconry) could be an } \\
\text { effective management tool to reduce nuisance Egyptian geese Alopochen } \\
\text { aegyptiaca. We hypothesised that falconry would result in elevated fear } \\
\text { levels of geese, resulting in increased vigilance levels, reduced favorability } \\
\text { of the site and locally reduced abundance. We conducted our study on } \\
\text { three golf courses (one treatment and two controls) in the Western Cape, } \\
\text { where they are considered a pest species. Our treatment involved flying } \\
\text { the Harris's hawk directly at geese from golf carts. Vigilance levels and } \\
\text { goose numbers were monitored before, during and after treatment. Goose } \\
\text { vigilance levels at the treatment site increased by } 76 \% \text { and their numbers } \\
\text { declined by 73\% following falconry. No changes were observed at either } \\
\text { control site. Although the hawks killed some geese, the decreases in } \\
\text { abundance were almost three times greater than the numbers killed, } \\
\text { indicating that indirect effects were considerably larger than the direct } \\
\text { effect of mortality. During the treatment period vigilance levels were } \\
\text { markedly higher in the presence of a golf cart, suggesting that geese } \\
\text { learned to associate carts with the threat of predation. Post-treatment } \\
\text { vigilance levels reduced significantly compared to levels detected during } \\
\text { the treatment period and goose numbers on the experimental site } \\
\text { increased rapidly, returning to pre-treatment levels within two months. Our }\end{array}$ \\
\hline
\end{tabular}


results demonstrate the efficacy of falconry to reduce nuisance bird numbers and suggest there may be other applications where the deployment of trained predators can be used to mitigate negative humanwildlife interactions.

SCHOLARONE $^{\text {m }}$
Manuscripts 
13.04.16

Alex Atkins

Percy FitzPatrick Institute of African Ornithology.

Percy FitzPatrick Institute of African Ornithology, DST-NRF Centre of Excellence, University of Cape Town, Rondebosch., Cape Town, 7701, South Africa

$+27(0) 216503304$

alex.zander.atkins@gmail.com

Atkins et al. Experimentally Manipulating the Landscape of Fear

\section{Experimentally Manipulating the Landscape of Fear to Manage Problem Animals.}

ALEX ATKINS ${ }^{1}$, Percy FitzPatrick Institute of African Ornithology, DST-NRF Centre of Excellence, University of Cape Town, Rondebosch., Cape Town, 7701, South Africa

STEPHEN M. REDPATH, Institute of Biological and Environmental Science, University of Aberdeen, Zoology Building, Tillydrone Avenue., Aberdeen, AB24 2TZ, UK. s.redpath@abdn.ac.uk

ROB M. LITTLE, Percy FitzPatrick Institute of African Ornithology, DST-NRF Centre of Excellence, University of Cape Town, Rondebosch., Cape Town, 7701, South Africa. rob.little@uct.ac.za

ARJUN AMAR, Percy FitzPatrick Institute of African Ornithology, DST-NRF Centre of Excellence, University of Cape Town, Rondebosch., Cape Town, 7701, South Africa. arjun.amar@uct.ac.za

ABSTRACT Negative interactions between humans and wildlife are increasing, often leading to conflict between different stakeholders over appropriate management interventions; therefore effective and acceptable methods of pest and nuisance wildlife management are urgently sought. This study adopts a mechanistic approach, using knowledge of animal behavior, to develop and apply management tools aimed at solving important management issues. We experimentally tested whether introducing trained Harris's hawks Parabuteo unicinctus (through falconry) could be an effective management tool to reduce

\footnotetext{
${ }^{1}$ Email: alex.zander.atkins@gmail.com
} 
1 Atkins et al.

29 nuisance Egyptian geese Alopochen aegyptiaca. We hypothesised that falconry would result

30 in elevated fear levels of geese, resulting in increased vigilance levels, reduced favorability of

31 the site and locally reduced abundance. We conducted our study on three golf courses (one

32 treatment and two controls) in the Western Cape, where they are considered a pest species.

33 Our treatment involved flying the Harris's hawk directly at geese from golf carts. Vigilance

34 levels and goose numbers were monitored before, during and after treatment. Goose vigilance

35 levels at the treatment site increased by $76 \%$ and their numbers declined by $73 \%$ following

36 falconry. No changes were observed at either control site. Although the hawks killed some

37 geese, the decreases in abundance were almost three times greater than the numbers killed,

38 indicating that indirect effects were considerably larger than the direct effect of mortality.

39 During the treatment period vigilance levels were markedly higher in the presence of a golf

40 cart, suggesting that geese learned to associate carts with the threat of predation. Post-

41 treatment vigilance levels reduced significantly compared to levels detected during the

42 treatment period and goose numbers on the experimental site increased rapidly, returning to

43 pre-treatment levels within two months. Our results demonstrate the efficacy of falconry to

44 reduce nuisance bird numbers and suggest there may be other applications where the

45 deployment of trained predators can be used to mitigate negative human-wildlife interactions.

46 KEYWORDS: Alopochen aegyptiaca; Egyptian goose; Cape Town; falconry; landscape of

47 fear; nuisance species; predator-prey dynamics; predation risk. 
2 | Atkins et al.

51 While global biodiversity continues to decline (Butchart et al. 2010), some species benefit

52 from the continued anthropogenic induced changes to the environment to the extent their

53 populations create management challenges (Fall and Jackson 1998, (Messmer 2009).

54 European Starlings (Sturnus vulgaris) for example, can roost in large numbers in urban areas

55 causing damage to buildings, whilst deer (Cervus spp), rabbits (Oryctolagus spp), rats (Rattus

56 spp) and geese (Branta spp) can cause agricultural damage (Thearle 1968, Conover 2002,

57 Leirs 2003, Hall and Gill 2005). Acceptable and effective, empirically based management

58 solutions are urgently sought (Baruch-Mordo et al. 2011).

59 An array of lethal and non-lethal management techniques that vary in their efficacy have

60 been employed to regulate problem animal populations, (Woodroffe et al. 2005). The use of

61 lethal control is often controversial due to the public's negative perception of such measures

62 (Conover and Chasko 1985, Loker et al. 1999, Ayers et al. 2010). Non-lethal control options

63 such as the use of chemical repellents (Cummings et al. 1991), translocation (Massei et al.

64 2010), the establishment of alternative feeding areas or food sources (Redpath et al. 2001),

65 providing economic compensation (MacLennan et al. 2009), exclusion of animals from

66 designated areas (Graham and Ochieng 2008) and various methods of 'hazing', or persistent

67 harassment (Conover and Chasko 1985, Castelli and Sleggs 2000), are often deemed more

68 desirable (Coluccy et al. 2001, Shivik 2004). However, habituation to non-lethal methods has

69 been cited as a major inadequacy, limiting their efficacy (Shivik 2004) which has resulted in

70 an ongoing search for an effective and acceptable method for managing pest populations.

71 The fear of living with predators is known to have powerful effects on individuals and

72 populations of prey species (Ripple and Beschta 2004, Laundre et al. 2010). When predators

73 are present, prey become more vigilant and ultimately avoid areas of high predator density

74 even at the cost of good foraging opportunities (Mao et al. 2005; Cresswell 2008; Sansom et

75 al. 2009). By monitoring the amount of time nuisance animals spend being vigilant, we can, 
3 | Atkins et al.

76 by proxy, determine whether the habitat is one that they perceive to be relatively safe. In

77 situations where this is the case, the manipulation of fear has the potential to assist in the 78 management of these problematic species.

79 Fear and predation risk can be increased by using falconry which is based on the idea that 80 birds of prey can have lethal and non-lethal effects on prey population densities. Falconry has 81 been applied to control pest birds, in residential and commercial settings (Erickson et al. 82 1990;), to reduce bird strikes by aircraft at airbases (McDonald 2001), to control gull 83 populations at industrial sites (Blokpoel and Tessier 1987), to reduce corvid and gull numbers 84 at landfill sites (Baxter and Allan 2006; Baxter and Robinson 2007), and to deter birds from 85 crops (Daugovish and Yamomoto 1996). Despite these widespread applications, scientific 86 evidence on the efficacy of falconry as an ecological tool is scarce. Two studies have been 87 conducted at landfill sites in the UK, involving pseudo-experimental trials (Baxter and Allan 88 2006; Cook et al. 2008), and other studies have evaluated the efficacy of falconry to reduce 89 nuisance bird populations on airfield sites (Chamorro and Clavero, 1994; Kitowski et al. 90 2010). These studies have suggested the success of falconry is largely site-specific, dependent on the type of raptor used, and is most effective when used in conjuction with other hazing techniques. While such pseudo-experimental studies are easier to implement, stronger

93 inferences can be achieved through manipulative experiments with both spatial and temporal 94 controls (Macnab 1983, Walters and Holling 1990; Johnson 2002; Reddiex and Forsyth 95 2006). Therefore, we aimed to experimentally test the efficacy of using trained birds of prey 96 as agents of fear in an otherwise relatively safe habitat to reduce the local abundance of prey 97 as a result of non-consumptive effects of predation.

98 In South Africa, populations of Egyptian geese (Alopochen aegyptiaca) (Linnaeus, 1766)

99 have increased in recent decades (Mangnall and Crowe 2002), and are now regularly located 100 in urban green spaces (e.g. golf courses in numbers exceeding hundreds of individuals 
4 | Atkins et al.

101 (Mackay et al. 2014). Large numbers of geese have created a significant problem for golf 102 course managers, with concerns ranging from green and fairway damage, noise pollution, and 103 harassment of native birdlife (Little and Sutton 2013).

104 We monitored goose vigilance levels and abundance at three golf courses before and after 105 introducing falconry at one of these sites, while keeping the remaining two as controls. Also, 106 we continued monitoring at the experimental site after the falconry had ceased. We 107 hypothesised that exposing the geese to regular predator encounters at the treatment site 108 would alter their perception of predation risk and their landscape of fear which would be 109 reflected in a change in local habitat use, with geese moving away from the treatment site. 110 We predicted an increase in their vigilance levels and a reduction in goose numbers at the 111 treatment site relative to our control sites. Furthermore, because the raptors were flown from 112 golf carts, we predicted that increase in vigilance levels at the experimental site would be 113 more pronounced and sustained in the presence of golf carts than at the control sites. 
5 | Atkins et al.

114 STUDY AREA

115 The study was conducted at three golf courses in the Western Cape, South Africa. Two golf

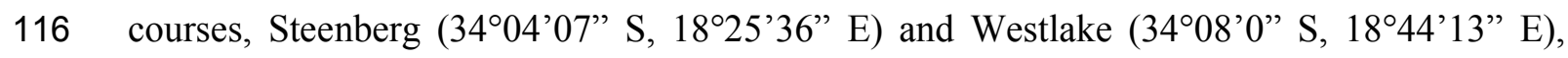

117 were control sites, where no falconry was conducted. The treatment site was conducted at

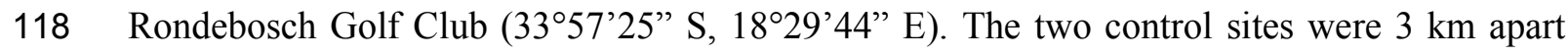

119 and were $15 \mathrm{~km}$ from the experimental site, all sites were located in suburban areas of Cape

120 Town. Westlake and Steenberg golf courses were located close to the Zandvlei and

121 Strandfontein wetlands, which were important areas of safety for roosting and moulting geese

122 (Ndlovu et al. 2013). Rondebosch golf course is intersected by the Black River, and is close

123 to three other golf coursesand the Raapenberg bird sanctuary, which all offer suitable habitat

124 for Egyptian geese. On average the golf courses occupy 50-60 ha (Fox and Hockey 2007)

125 and were used daily from sunrise until sunset throughout the year.

126 METHODS

127 We recorded Egyptian goose vigilance behaviour once per week for 26 weeks at each golf 128 course between mid-June 2014 and mid-January 2015, with an additional eight weeks of 129 vigilance observations post-falconry at Rondebosch. The same methodology as used by 130 Mackay et al. (2014) were followed and are detailed here. Vigilance filming was conducted 131 on groups of geese of three or more birds. On most occasions, each filming day consisted of 132 five filming bouts (watch-bouts), each of 15 minutes in duration. Watch-bouts were randomly 133 spread throughout the afternoon, between 1200 and 1800, and with a similarly even spread 134 for each golf course. We conducted 122 watch-bouts at Steenberg, 107 at Westlake, and 137 135 at Rondebosch. Different groups of geese were filmed for each of the five watch bouts to 136 minimise pseudo-replication (Hurlbert 1984). Filming took place during the afternoons when 137 the birds forage most actively (Halse 1985). Sleeping geese were not recorded. A Panasonic 138 SDR-S50 video camera (Panasonic Corporation, Osaka, Japan) mounted on a 1.7-m tripod 
6 | Atkins et al.

139 was used to record footage of the geese. The cameras and golf carts were positioned at least

$14010 \mathrm{~m}$ from the geese, so the observer did not influence vigilance behaviour (Mackay et al.

141 2014). For each watch-bout, the observer filmed the geese either on foot or from a golf cart.

142 The filming was divided as evenly as possible between these two methods. The observer

143 recorded the group size and the filming method for each watch-bout.

144 Vigilance behaviour was characterized as visual scanning performed by the geese, which 145 increases the probability of detecting predators (Dimond and Lazarus 1974). Thus, a goose 146 was deemed vigilant if its head was above the level of its back and non-vigilant when its head 147 was below body level, which is a suitable assumption considering the foraging strategy of 148 Egyptian geese (Barbosa 2002). Each watch-bout was paused at ten second intervals and the 149 proportions of vigilant (heads up) geese and non-vigilant (heads down) geese within the 150 frame were counted. For each watch-bout, we calculated the sum of the number of vigilant 151 and non-vigilant geese recorded, which was used as the response variable in subsequent data 152 analyses. Also, we recorded the number of geese in the group (which may differ from the 153 numbers being filmed at any one time of the watch-bout). A group was defined as all birds 154 within $30 \mathrm{~m}$ of one another. During the watch-bout, any observations occurring during a 155 major disturbance to geese by golfers, a golf cart, lawn mowers or ground staff were 156 excluded to ensure that the vigilance levels of the geese being observed reflected natural 157 behaviour rather than vigilance initiated by human presence.

158 Absolute counts of Egyptian geese on each course were conducted twice per week for 29 159 weeks, between mid-June 2014 and mid-January 2015, and for an additional eight weeks at 160 the experimental site following the cessation of falconry. Geese were counted from a golf cart 161 along a pre-mapped route to avoid double counting. Counts were randomly spread throughout 162 the morning, between 0600 and 1200, and the timing of counts was similar for each golf 163 course. We conducted 54 counts at Steenberg, 56 at Westlake, and 60 at Rondebosch. 
7 | Atkins et al.

164 Additionally, at Rondebosch we carried out an additional 13 counts post-falconry. No 165 additional counts were conducted at the two control sites because goose management 166 activities changed at these sites after the treatment period and we could no-longer use these as 167 viable control sites. Flightless goslings were not included in the final count data.

168 Falconry was conducted by independent registered falconers (Avian Pest Control (Pty) Ltd, 169 trading as Raptor Force) with trained Harris's hawks (Parabuteo unicinctus) (Temminck 170 1824). Two different birds were used in the treatment. The falconer's objective was to harass 171 the geese rather than to kill them.

172 Falconry was conducted for nine weeks, from 10 November 2014 until 10 January 2015. 173 The first month involved a relatively persistent presence of the hawk at the course. Thus, 174 falconry took place for a minimum of one hour a day, five days a week for the first week, 175 reducing to one treatment day per week by weeks seven to nine (Fig. 1).The hawk was 176 always flown from a golf cart. The handler and the hawk led in the front cart, whilst the data 177 recorder followed in a second cart. The falconer approached the geese in the cart and released 178 the hawk (an attack flight, referred to hereafter as a slip) onto the geese from varying 179 distances so as to avoid potential habituation. Target areas within the golf course were chosen 180 according to where geese had been seen during counts, and to ensure comprehensive 181 coverage of the entire golf course throughout the study period.

182 All population counts and vigilance filming undertaken at the treatment site were 183 undertaken at times when no falconry was taking place.

\section{Data analysis}

185 Statistical analyses were carried out using the statistical package $\mathrm{R}$ version 3.1 .2 (R 186 Development Core Team 2014). Means are presented with upper and lower 95\% confidence 187 limits. 
8 | Atkins et al.

188

189

190

191

192

193

194

195

196

197

198

199

200

201

202

203

204

205

206

207

208

209

210

211

212

In all analyses of vigilance levels, we used a generalised linear mixed-effects (GLMM) model using the lme4 package in $\mathrm{R}$ (Bates et al. 2014), fitted with a binomial error distribution. In all models, we controlled for the non-independence of records taken on the same day, by including the day on which filming took place at each site as a random effect. Our binomial response variable was the sum of the number of vigilant geese and the number of non-vigilant geese for each watch-bout. A previous analysis indicated an effect of group size on Egyptian goose vigilance levels (Mackay et al. 2014). Therefore, before examining for an effect of treatment on vigilance levels, we controlled for the initial group size during each watch-bout to test whether vigilance differed at each site before or during the treatment period. The model included the following fixed effect terms - site, treatment (two-level factor: pre-treatment and treatment) and the interaction between site and treatment.

Because hawks were flown at the geese from golf carts, we predicted that geese may associate the potential predation risk with the presence of a cart and become more vigilant around carts in general at the treatment site. Therefore we explored whether there were differences between vigilance levels filmed on foot, or from a cart, before and during the treatment period at the different sites. To do this we fitted a three-way interaction between site, treatment (before/during) and filming method (foot/cart). We additionally had information on the vigilance levels at the experimental site following the end of falconry. To explore how these levels changed, we used the model with data only from the treatment site and examined this using a three-level factor (pre-treatment, treatment and post-treatment) with the same binomial GLM.

Counts of Egyptian geese were analysed using a Generalised Linear Model (GLM), fitted with a Poisson error distribution. We tested for significant differences in the abundance of Egyptian geese between sites, and for an interaction between site and goose counts before and during the treatment period, our prediction was that if falconry was effective, reductions 
9 | Atkins et al.

213 in goose numbers would be greater at the treatment site during the period when falconry was 214 being implemented compared to the control sites. Therefore, the model included the 215 following fixed effect terms: site, treatment (two-level factor: pre-treatment and treatment) 216 and the interaction between site and treatment. Where a significant interaction was detected, 217 we used a pairwise comparison to test between sites before and during the treatment period, 218 using the LSmeans package (Lenth 2015). Additionally, we analysed goose abundance at the 219 experimental site following the end of falconry. To explore how these levels changed we 220 used the model with data only from the treatment site and examined this using three-level 221 factor (pre-treatment, treatment and post-treatment) with the Poisson GLM. 
10 Atkins et al.

\section{RESULTS}

223 A Harris's Hawk was flown at geese 123 times at the treatment site. Goose fatalities $(\mathrm{n}=41)$ 224 during this period averaged nine geese per week for the first three weeks, and two geese per 225 week for the remaining seven weeks (Fig. 1).

226 After controlling for the influence of group size, there was a significant interaction 227 between site and treatment $\left(\chi^{2}=32.5, \mathrm{df}_{2,358}, P=<0.01\right)$ on vigilance levels (Fig. 2$)$. There 228 was a significant increase in vigilance at the Rondebosch treatment site $(\mathrm{Z}=5.6, P=<0.01)$, 229 from 0.21 of the geese being vigilant pre-treatment (95\% CL 0.178-0.244), to 0.37 (95\% CL 230 0.324-0.416), equivalent to an approximate increase of $76 \%$. Conversely, between this period 231 there was a significant decrease $(Z=-2.3, P=0.02)$ in mean vigilance levels at the Steenberg 232 control site from 0.20 (95\% CL $0.170-0.230)$ to 0.14 (95\% CL $0.116-0.180)$. No change in 233 vigilance level was recorded at Westlake $(Z=-0.5, P=0.63)$ (before: 0.161 (95\% CL 0.135234 0.188; during: 0.150 (95\% CL 0.120-0.188)). Examining vigilance levels at the treatment site 235 across the three periods, we detected significant differences in vigilance levels between the 236 pre-treatment, treatment and post-treatment period $\left(\chi^{2}=19.9, \mathrm{df}_{2,181}, P=<0.01\right)$. Vigilance 237 levels post-treatment reduced to 0.26 (95\% CL 0.21-0.32) (Fig. 2) which was significantly 238 different from the vigilance levels during the treatment period $(\mathrm{Z}=-0.5, P=0.01)$ and similar 239 to the vigilance levels pre-treatment $(\mathrm{Z}=-2.6, P=0.16)$.

240 Before falconry, goose numbers at the three sites showed similar fluctuation, with a 241 generally increasing trend (Fig. 3). However, during this pre-treatment period, there were, on 242 average, 50\% fewer geese at the experimental site (Rondebosch: $\bar{x}=100$ (95\% CL 97-103)) 243 than at either of the control sites (Steenberg: $\bar{x}=208$ (95\% CL 203-213) and Westlake: $\bar{x}=$ $244211(95 \%$ CL 207-216)). Following the introduction of falconry in November, the mean 245 abundance of geese at the treatment site fell rapidly from 148 geese to only eight geese within 
11 Atkins et al.

246 two weeks, and remained below 30 geese with a mean of 27 individuals for the duration of

247 the treatment period (Fig. 3).

248 We detected a significant interaction between sites during the pre-treatment and treatment 249 periods $\left(\chi^{2}=808, \mathrm{df}_{2,187}, P=<0.01\right)$ (Fig. 4). Mean numbers of geese increased significantly 250 at the two control sites during the treatment period. At Steenberg geese increased from 208 251 individuals (95\% CL 203-213) before treatment, to 297 individuals (95\% CL 289- 304) 252 during the treatment period $(\mathrm{Z}=19.8, P=<0.01)$, while at Westlake mean numbers increased 253 from 211 (95\% CL 207-216) to 280 (95\% CL 272-288) ( $\mathrm{Z}=15.6, P=<0.01)$. Conversely, at 254 the treatment site there was a significant decrease in mean goose numbers from 100 255 individuals (95\% CL 97-103) pre-treatment to 27 individuals (95\% CL 25-29) during 256 treatment $(\mathrm{Z}=-19.9, P=<0.01)$, representing a reduction in mean abundance of c. $73 \%$ (Fig. 257 3). After falconry ceased, the abundance of geese at the treatment site increased rapidly (Fig. 258 3). Examining the counts at the treatment site alone across all three treatment periods, we 259 detected significant differences $\left(\chi^{2}=1539, \mathrm{df}_{2,70}, P=<0.01\right)$. The mean abundance of 129 260 individuals (95\% CL 123-135), post treatment was significantly greater than the mean during 261 treatment $(\mathrm{Z}=-32.7, P=<0.01)$ and similar to the vigilance levels pre-treatment $(\mathrm{Z}=-2.6, p$ $262=0.16)($ Fig. 4).

263 Following the introduction of falconry, vigilance levels at the experimental site were 264 highest when filmed from a cart $(+140 \%)$ compared to when filmed on foot $(+25 \%)$, a 265 relationship not detected at the control sites (Fig. 2 and Table 1). The three-way interaction 266 between site, treatment period (pre-treatment/treatment) and filming method (on foot or by 267 cart) was significant $\left(\chi^{2}=504.3, \mathrm{df}_{2,353}, P=<0.01\right)$ (Fig. 2 and Table 1$)$. In fact, at the 268 treatment site pre-treatment vigilance was significantly lower when filmed from a cart $(0.187$ 269 vigilance (95\% CL $0.158-0.220)$ ) than when filmed on foot (0.236 vigilance (95\% CL 0.201 270 0.270) $(\mathrm{Z}=-8.7, P=<0.01)$. However, mean vigilance levels during treatment were 
12 | Atkins et al.

271 significantly greater $(\mathrm{Z}=24, P=<0.01)$ when filmed from a cart $(0.452$ vigilance $(95 \% \mathrm{CL}$

$2720.403-0.50)$ ) than when filmed on foot (0.285 vigilance (95\% CL 0.245-0.270)). Post-

273 treatment, vigilance levels filmed from a cart decreased by $41 \%$ to a mean of 0.265 (95\% CL

274 0.211-0.327) and were significantly lower than the vigilance levels recorded from a cart

275 during the treatment period $(\mathrm{Z}=4.2, P=<0.01)$. However, vigilance levels in the presence of

276 a cart were more than $40 \%$ higher than pre-treatment levels $(Z=-2.3, P=0.02)$. In contrast,

277 vigilance levels at the treatment site filmed on foot during the post-treatment period $(0.242$

278 vigilance $(95 \%$ CL $0.192-0.301))$ were similar to those recorded before $(\mathrm{Z}=-0.2, P=0.85)$ and

279 during treatment $(\mathrm{Z}=1.1, P=0.27)$.

280 
13 | Atkins et al.

281

282 The use of trained birds of prey can significantly alter the perceived risk of predation among

283 Egyptian geese as demonstrated by the significantly higher levels of vigilance recorded under

treatment conditions than those during non-treatment conditions and at control sites. During

285

286

287

288

289

290

291

292

falconry, vigilance levels at the treatment site increased by $76 \%$ and vigilance levels post treatment reverted to levels similar to those observed at the control sites during the pretreatment period. However this did not happen immediately, indicating that some geese remained cautious for some time after the cessation of falconry. As far as we are aware, this is the first study to demonstrate changes in anti-predator behaviour in a target species as a result of falconry. Our results are consistent with modelled results (Bednekoff and Lima 1998) and empirical studies in avian species (Devereux et al. 2005) and mammals (Laundre et al. 2001; Li et al. 2009).

During the month before the falconry experiment, mean goose abundance at the treatment site was 148 individuals. The mean abundance of geese during the entire treatment period was 27 individuals (95\% CL 25-29), representing an overall reduction of $73 \%$ when compared to the entire non-treatment period and $82 \%$ when compared to the mean goose abundance during the month preceding falconry. This decrease in goose abundance can largely be attributed to the non-lethal effects of predation pressure, the initial lethal impact representing just $14 \%$ of the initial reduction. Predator avoidance by habitat selection is widespread in the animal kingdom and has been demonstrated to occur in a variety of taxa (Ripple and Beschta 2004; Mao et al. 2005; Cresswell and Whitfield 2008). This experiment demonstrates that falconry is an effective application of this naturally occurring phenomenon, and can be used as a management tool to manipulate the risk of predation perceived by geese and other nuisance species to reduce their numbers. Earlier studies describe the success of falconry as site-specific and dependent upon the species of raptor used (Daugovish and 
14 | Atkins et al.

306 Yamomoto 1996; Baxter and Allan 2006; Kitowski et al. 2011), citing habituation as a major

307 inadequacy (Cook et al. 2008; Soldatini et al. 2008). While fatalities in this study were higher

308 than anticipated, they were reduced dramatically after the first two weeks of falconry to two

309 individuals per week, which reinforces that no habituation to falconry occurred.

310 We predicted that the geese could learn to associate golf carts with the threat of predation

311 since the hawks were always flown from the cart. While vigilance levels at the experimental

312 site increased during falconry, there was a $140 \%$ increase in mean vigilance when the geese

313 were filmed from the cart compared to an average increase in vigilance of just $25 \%$ when

314 filmed on foot. Furthermore, there was still some recognition of a possible threat posed by the

315 cart for some time after the cessation of the falconry. This was the reverse prior to treatment,

316 where geese were more vigilant in the presence of an observer on foot than when in a cart.

317 Our results demonstrate that geese became conditioned to fear golf carts as an indicator of 318 increased predator risk.

319 Learning is widespread in the animal kingdom; many species alter their behaviour as a 320 result of environmental information (Dukas 1998) and predator avoidance behaviour is 321 known to improve with experience (Griffin 2004). Learning to respond to the cart as a 322 potential threat is a form of associative learning traditionally referred to as classical 323 conditioning, whereby a biologically insignificant event or object (the conditional stimulus), 324 in this case the cart, is paired with a biologically significant event (Pavlov 1927), in this case 325 an attack by a predator. Conditioned fear responses have been observed in a number of 326 studies (Herzog and Hopf 1984; Chivers and Smith 1995; McLean et al. 1999). Golf carts are 327 in constant use on a golf course, using them to release the hawk manipulated a previously 328 neutral feature of this habitat, turning the carts into a new source of potential risk. The overall 329 effect of falconry is enhanced, as geese become more vigilant in close proximity to a cart and 
15 | Atkins et al.

330 are able to devote less time to foraging, thus further reducing the overall attractiveness of the 331 habitat.

332 The results of this study, while they appear to be convincing are based on one treatment 333 replicate. Stronger inferences can be made from experimental designs that consist of 334 replicated treatment and control areas (Hurlbert 1984; Reddiex and Forsyth 2006; Prosser 335 2010). Due to the logistical problems of having more than one replicate treatment site for this 336 study, the control site was instead replicated (Oksanen 2001). Additionally our results are 337 backed up by changes in the levels of vigilance and strengthened by our post-treatment 338 monitoring which showed that numbers and vigilance returned to pre-treatment levels 339 following the end of falconry.

340

\section{MANAGEMENT IMPLICATIONS}

342 From a management perspective, it is important to note that falconry needs to be 343 continuously applied to remain effective, evidenced by the post-treatment decrease in 344 vigilance and increase in abundance (Figs 2 and 4). While an expensive option for wildlife 345 managers the frequency of falconry visits can be reduced without compromising the efficacy 346 of the technique as long as habituation is avoided. Previous studies reported the need to 347 combine a number of methods of control to avoid habituation (Cook et al. 2008; Soldatini et 348 al. 2008). Incorporating even a very low level of lethality can effectively instil enough of a 349 consequence to ensure habituation is avoided (Baxter and Allan 2007). While we did not 350 observe any habituation, we hypothesise that, while the non-lethal effect of falconry is demonstrably strong, its efficacy as a tool may indeed be reliant upon reinforcement, instilled by the few but regular instances of fatalities. Future studies would benefit from testing the efficacy of such tools under strictly non-lethal conditions. 
16 | Atkins et al.

354 Recent research has highlighted the importance of adopting a mechanistic approach, using 355 knowledge of animal behaviour to develop tools to solve critical conservation and 356 management problems (Blumstein and Berger-Tal 2015). In addition, it is vitally important 357 when applying mechanistic knowledge to management problems, to evaluate the efficacy of 358 management actions, with emphasis on experimental design (Walters and Holling 1990; 359 Redpath 2013; Blumstein and Berger-Tal 2015). This study has demonstrated the merit of 360 such an approach and our results indicate there may be other applications where the use of 361 trained birds of prey can be used to mitigate negative human-wildlife interactions. 
17 | Atkins et al.

362 ACKNOWLEDGMENTS

363 We thank A. Clemo and H. Chalmers of Raptor Force for allowing us to observe their

364 falconry activities. F. Fazey, F. Morling and S. Abdu for their field assistance. We thank the

365 golf course managers for access to the courses and support throughout, in particular W. Hill 366 at the Rondebosch Golf Club.

367

368 The methods used in this study were approved by the University of Cape Town Science 369 Faculty Animal Research Ethics Committee (protocol number 2014/V22/AA). Funding for 370 the project was gratefully received from the DST-NRF Centre of Excellence fund, University 371 of Cape Town. The authors have no conflict of interest to declare. 
18 Atkins et al.

\section{LITERATURE CITED}

373 Ayers, C. R., C. E. Moorman, C. S. Deperno, F. H. Yelverton, and H. J. Wang. 2010. Effects

374 of mowing on Anthraquinone for deterrence of Canada Geese. Journal of Wildlife $375 \quad$ Management 74:1863-1868.

376 Barbosa, A. 2002. Does vigilance always covary negatively with group size? Effects of 377 foraging strategy. acta ethologica 5:51-55.

378 Baruch-Mordo, S., S. W. Breck, K. R. Wilson, and J. Broderick. 2011. The carrot or the 379 stick? Evaluation of education and enforcement as management tools for human380 wildlife conflicts. PLoS ONE 6: e15681

381 Bates D., M. Maechler, B. Bolker, and S. Walker. 2013. lme4: Linear Mixed-effects Models 382 Using Eigen and S4. R package version 1.1-0, URL http://lme4.r-forge.r-project.org/.

383 Baxter, A. T., and J. R Allan. 2006. Use of raptors to reduce scavenging bird numbers at $384 \quad$ landfill sites. Wildlife Society Bulletin 34:1162-1168.

385 Baxter, A. T., and A. P. Robinson. 2007 A comparison of scavenging bird deterrence 386 techniques at UK landfill sites. International Journal of Pest Management 53:347-356.

387 Bednekoff, P. A., and S. L. Lima. 1998. Re-examining safety in numbers: interactions 388 between risk dilution and collective detection depend upon predator targeting 389 behaviour. Proceedings of the Royal Society of London B: Biological Sciences $265: 2021-2026$

Blokpoel, H., and D. Tessier. 1987. Control of ring-billed gull colonies at urban industrial sites in sourthern Ontario, Canada. Thrird Eastern Wildlife Damage Control Conference 2:7-17.

Blumstein, D. T., and O. Berger-Tal. 2015. Understanding sensory mechanisms to develop effective conservation and management tools. Current Opinion in Behavioral Sciences 6:13-18 
19 | Atkins et al.

397 Butchart, S. H. M., M. Walpole, B. Collen, A. V. Strien, J. P. W. Scharlemann, R. E. A. 398 Almond, J. E. M Baillie, et al. 2010. Global biodiversity: indicators of recent 399 declines. Science 328:1164-1168.

400 Castelli, P. M., and S. E Sleggs. 2000. Efficacy of border collies to control nuisance Canada $401 \quad$ Geese. Wildlife Society Bulletin 28:385-392.

402 Chamorro, M., and J. Clavero. 1994. Falconry for bird control on airdromes: The Spanish 403 experiences after 26 years. Proceedings of Bird Strike Committee Europe 61:397-407.

404 Chivers, D. P., and J. F. Smith. 1995. Free-living fathead minnows rapidly learn to recognize 405 pike as predators. Journal of Fish Biology 46:949-954.

406 Coluccy, J. M., R. D. Drobney, D. A. Graber, S. L. Sheriff, and D. J. Witter. 2001. Attitudes 407 of central Missouri residents toward local giant Canada geese and management 408 alternatives. Wildlife Society Bulletin 29:116-123.

409 Conover, M. R. 2002. Resolving Human-Wildlife Conflicts: The Science of Wildlife 410 Damage Management. Lewis, Florida. USA.

411 Conover, M. R., and G. G. Chasko. 1985. Nuisance Canada Goose Problems in the Eastern $412 \quad$ United States. Wildlife Society Bulletin 13:228-233.

413 Cook, A., S. Rushton, J. Allan, and A. Baxter. 2008. An evaluation of techniques to control 414 problem bird species on landfill sites. Environmental management 41:834-43.

415 Cresswell, W. 2008. Non-lethal effects of predation in birds. Ibis 150:3-17.

416 Cresswell, W., and P. D. Whitfield. 2008. How starvation in Redshanks Tringa totanus 417 results in predation mortality from Sparrowhawks Accipiter nisus. Ibis 150:209-218.

418 Cummings, J. L., J. R. Mason, D. L Otis, and J. F. Heisterberg. 1991. Evaluation of 419 Dimethyl and Methyl Anthranilate as a Canada Goose repellent on grass. Wildlife $420 \quad$ Society Bulletin 19:184-190. 
Atkins et al.

421

422

423

424

425

426

427

428

429

430

431

432

433

434

435

436

437

438

439

440

441

442

443

444

445

Daugovish, O., and M. Yamomoto. 2006. Bird control in production strawberries with falconry. HortScience 41:1047

Devereux, C. L., M. J. Whittingham, E. Fernández-Juricic, J. A. Vickery, and J. R. Krebs. 2006. Predator detection and avoidance by starlings under differing scenarios of predation risk. Behavioral Ecology 17: 303-309.

Dimond, S., and J. Lazarus. 1974. The problem of vigilance in animal life. Brain, Behaviour and Evolution 9:60-79.

Dukas, R., editor. 1998. Evolutionary ecology of learning. Cognitive ecology: the evolutionary ecology of information processing and decision making. University of Chicago Press, Chicago, USA.

Erickson, W. A., R. E Marsh, and T. P. Salmon. 1990. A review of falconry as a bird-hazing technique. Proceedings of the Fourteenth Vertebrate Pest Conference 25:313-316.

Fall, M. W., and W. B. Jackson. 1998. A new era of vertebrate pest control? An Introduction. International biodeterioration and biodegradation, 42:85-91.

Fox, S. C., and P. A. R. Hockey. 2007. Impacts of a South African coastal golf estate on shrubland bird communities. South African Journal of Science 103:27-34.

Graham, M. D., and T. Ochieng. 2008. Uptake and performance of farm-based measures for reducing crop raiding by elephants Loxodonta Africana among smallholder farms in Laikipia District, Kenya. Oryx 42:76-82.

Griffin, A. S. 2004. Social learning about predators: a review and prospectus. Learning and Behavior 32:131-140.

Hall, G. P., and K. P. Gill. 2005. Management of wild deer in Australia. Journal of Wildlife Management 69:837-844.

Halse, S. A. 1985. Activity budgets of Spurwinged and Egyptian geese at Barberspan during winter. Ostrich 56:104-110. 
21 Atkins et al.

446 Herzog, M., and S. Hopf. 1984. Behavioural responses to species specific warning calls in 447 infant squirrel monkeys reared in social isolation. American Journal of Primatology $448 \quad 7: 99-106$.

449 Hurlbert, S .H. 1984. Pseudoreplication and the design of ecological field experiments. $450 \quad$ Ecological Monographs 54:187-211.

451 Johnson, D. H. 2002. The importance of replication in wildlife research. The Journal of $452 \quad$ Wildlife Management 66:919-932.

453 Kitowski, I., G. Grzywaczewski, J. Cwiklak, J. Grzegorzewski, and S. Krop. 2010. 454 Landscape and other ecological factors in bird strike risk management- the case study 455 456

Laundré, J. W., L. Hernández, and W. J. Ripple. 2010. The landscape of fear: Ecological implications of being afraid. The Open Ecology Journal 3:1-7.

Leirs, H. 2003. Management of Rodents in Crops: The Pied Piper and His Orchestra. Pages 183-190 in G. R. Singleton., L. A. Hinds., C. J. Krebs and D. M. Spratt, editors. Rats,

467 Li, Z., Z Jiang, and G. Beauchamp. 2009. Vigilance in Przewalski's gazelle: effects of sex, 468 predation risk and group size. Journal of Zoology 277:302-308. 
Atkins et al.

471 Loker, C. A., D. J. Decker, and S. J. Schwager. 1999. Social acceptability of wildlife

472 management actions in suburban areas: 3 cases from New York. Wildlife Society $473 \quad$ Bulletin 27:152-159.

474 Mackay, B., R. M. Little, A. Amar, and P. A. R. Hockey. 2014. Incorporating environmental 475 considerations in managing Egyptian Geese on golf courses in South Africa. The $476 \quad$ Journal of Wildlife Management 78: 671-678.

477 MacLennan, S. D., R. J. Groom, D. W. Macdonald, and L. G. Frank. .2009. Evaluation of a 478 compensation scheme to bring about pastoralist tolerance of lions. Biological $479 \quad$ Conservation 142:2419-2427.

480 Macnab, J. 1983. Wildlife management as scientific experimentation. Wildlife Society $481 \quad$ Bulletin 11:397-401.

482 Mangnall, M. J. and T. M. Crowe. 2002. Population dynamics and the physical and financial 483 impacts to cereal crops of the Egyptian Goose Alopochen aegyptiacus on the Agulhas 484 Plain, Western Cape, South Africa. Agriculture, Ecosystems and Environment 90:231485246.

486 Mao, J. S., M. S Boyce, D. W. Smith, F. J. Singer, D. J. Vales, J. M Vore, and E. H. Merrill. 487 2005. Habitat selection by elk before and after wolf reintroduction in Yellowstone 488 National Park. The Journal of Wildlife Management 69:1691-1707.

489 Massei, G., R. J. Quy, J. Gurney, and D. P. Cowan. 2010. Can translocations be used to 490 mitigate human-wildlife conflicts? Wildlife research 37:428-439.

491 McDonald, D. 2001. Urban bird management: an evaluation at the millennium. International 492 Pest Control 43:20-23.

493 McLean, I. G., C. Hölzer, and B. J. S. Studholme. 1999. Teaching predator-recognition to a 494 naive bird: Implications for management. Biological Conservation 87:123-130. 
Atkins et al.

Messmer, T. A. 2009. Human-wildlife conflicts: emerging challeneges and opportunities. Human-Wildlife Conflicts 3:10-17.

Ndlovu, M., G. S. Cumming, P. A. R Hockey, M. D. Nkosi, and G. L. Mutumi. 2013. A study of moult-site fidelity in Egyptian Geese, Alopochen aegyptiaca, in South Africa. African Zoology 48:240-249.

Oksanen, L. 2001. Logic of experiments in ecology: is pseudoreplication a pseudoissue? Oikos 94:27-38.

Pavlov, I. P. 1927. Conditioned reflexes. Oxford University Press, New York, USA.

Prosser, J. I. 2010. Replicate or lie. Environmental Microbiology 12:1806-1810.

R Core Team. (2014) R: A language and environment for statistical computing. R Foundation for Statistical Computing, Vienna, Austria. URL http://www.R-project.org/.

Reddiex, B. A., and D. M. Forsyth. 2006. Control of pest mammals for biodiversity protection in Australia . II . Reliability of knowledge. Wildlife Research 33:711-717.

Redpath, S. M., S. J. Thirgood, and F. M Leckie. 2001. Does supplementary feeding reduce predation of red grouse by hen harriers? Journal of Applied Ecology 38:1157-1168.

Redpath, S. M., J. Young, A. Evely, W. M. Adams, W. J. Sutherland, A. Whitehouse, A. Amar, R. A. Lambert, J. D. C. Linnell, A. Watt, and R. J. Gutierrez. 2013. Understanding and managing conservation conflicts. Trends in ecology and evolution 28:100-109.

Ripple, W. J., and R. L Beschta. 2004. Wolves and the ecology of fear: Can predation risk structure ecosystems? BioScience 54:755.

Sansom, A., J. Lind, and W. Cresswell. 2009. Individual behavior and survival: the roles of predator avoidance, foraging success, and vigilance. Behavioral Ecology arp110:1-7. 
24 Atkins et al.

518 Shivik, J. A. 2004. Non-lethal alternatives for predation management. Sheep and Goat $519 \quad$ Research Journal 19: 64-71.

520 Soldatini, C., Y. V. Albores-Barajas, P. Torricelli, and D. Mainardi. 2008. Testing the 521 efficacy of deterring systems in two gull species. Applied Animal Behaviour $522 \quad$ Science 110:330-340.

523 Thearle, R. J. P. 1968. Urban bird problems: The Problems of Birds as Pests. Symposia of 524 the Institute of Biology 17:181-197

525 Walters, C. J., and C. S. Holling. 1990. Large-scale management experiments and learning $526 \quad$ by doing. Ecology 71:2060-2068.

527 Woodroffe, R., S. Thirgood, and A. Rabinowitz. 2005. People and Wildlife: Conflict or Co528 Existence? Cambridge University Press.

529

530 Associate Editor: 
25 | Atkins et al.

$531 \quad$ Figure captions:

532 Figure. 1. Numbers of days per week that falconry was carried out (bars), the number of slips 533 (attack flights) per week $(\bullet$ ) and the number of Egypitian goose (Alopochen aegyptiaca) 534 fatalities per week (- - $\mathbf{\Delta}--)$. All falconry was carried out with a Harris's hawk (Parabuteo 535 unicinctus) flown during the nine weeks between 10 November 2014 and 10 January 2015 at 536 the Rondebosch Golf Club, Cape Town, South Africa.

537 Figure. 2. Mean proportion vigilance for Egyptian geese (Alopochen aegyptiaca) before and 538 after the treatment at both control sites (dashed lines) and the treatment site (solid lines). 539 Vigilance levels when filmed on foot (open circles) compared to when filmed from a cart 540 (open triangles) are contrasted for each site. The means and their $95 \%$ confidence limits 541 depicted are the results of a generalised linear model. The interaction between site, 542 before/during treatment and by cart/on foot was significant $(\mathrm{p}=<0.01)$. The effect of group 543 size and random variations between watch days were controlled for.

544 Figure. 3. Twice weekly averages of Egyptian geese counts (Alopochen aegyptiaca) 545 (Alopochen aegyptiaca) at both control sites (dashed lines) and at the treatment site (solid 546 line). Vertical dashed lines indicate the falconry treatment period between 10 November 2014 547 and 10 January 2015 which occurred at the experimental site (Rondebosch Golf Club).

548 Figure. 4. Mean abundance of Egyptian geese (Alopochen aegyptiaca) before and during the 549 treatment period at both control sites (dashed lines) and at the treatment site (solid line) as 550 well as post-treatment at the experimental site (Rondebosch Golf Club). The means and their $55195 \%$ confidence limits depicted are the results of a general linear model. The interaction 552 between site and treatment (before/after) was significant $(\mathrm{p}=<0.01)$. 
26 | Atkins et al.

554

555 Table 1. Mean vigilance of Egyptian geese (Alopochen aegyptiaca) filmed on foot and from

556 a golf cart at the three golf courses during the study period. Parameter estimates and

557 significance values of pairwise contrasts are also presented. 'Before' refers to pre-treatment

558 period and 'during' refers to the treatment period.

559

\begin{tabular}{|c|c|c|c|c|c|c|}
\hline \multirow[b]{3}{*}{ Site } & & \multicolumn{5}{|c|}{ On Foot } \\
\hline & \multicolumn{2}{|c|}{ before } & \multicolumn{2}{|c|}{ during } & \multicolumn{2}{|c|}{ before - during } \\
\hline & Mean vig & $95 \% \mathrm{Cl}$ & Mean vig & $95 \% \mathrm{Cl}$ & $Z$ ratio & $P$ Value \\
\hline Steenberg & 0.184 & $0.157-0.210$ & 0.156 & $0.124-0.190$ & -1.2 & 0.22 \\
\hline Westlake & 0.155 & $0.130-0.180$ & 0.161 & $0.123-0.200$ & 0.2 & 0.8 \\
\hline Rondebosch & 0.236 & $0.201-0.270$ & 0.285 & $0.245-0.330$ & 1.8 & 0.08 \\
\hline
\end{tabular}

\begin{tabular}{|c|c|c|c|c|c|c|}
\hline \multirow[b]{3}{*}{ Site } & \multicolumn{6}{|c|}{ By Cart } \\
\hline & \multicolumn{2}{|c|}{ before } & \multicolumn{2}{|c|}{ during } & \multicolumn{2}{|c|}{ before - during } \\
\hline & Mean vig & $95 \% \mathrm{Cl}$ & Mean vig & $95 \% \mathrm{Cl}$ & Z ratio & $P$ Value \\
\hline Steenberg & 0.211 & $0.181-0.240$ & 0.135 & $0.107-0.170$ & -3.3 & $<0.01$ \\
\hline Westlake & 0.168 & $0.141-0.200$ & 0.142 & $0.111-0.180$ & -1.1 & 0.27 \\
\hline Rondebosch & 0.187 & $0.156-0.220$ & 0.452 & $0.403-0.500$ & 8.8 & $<.01$ \\
\hline
\end{tabular}

560

561 Summary of conclusions and management implications

562 We demonstrate the efficacy of falconry to reduce nuisance bird numbers and highlight the 563 benefits of adopting a mechanistic approach, using knowledge of animal behavior, to develop 564 and apply management tools aimed at solving important management issues. 
Figure. 1

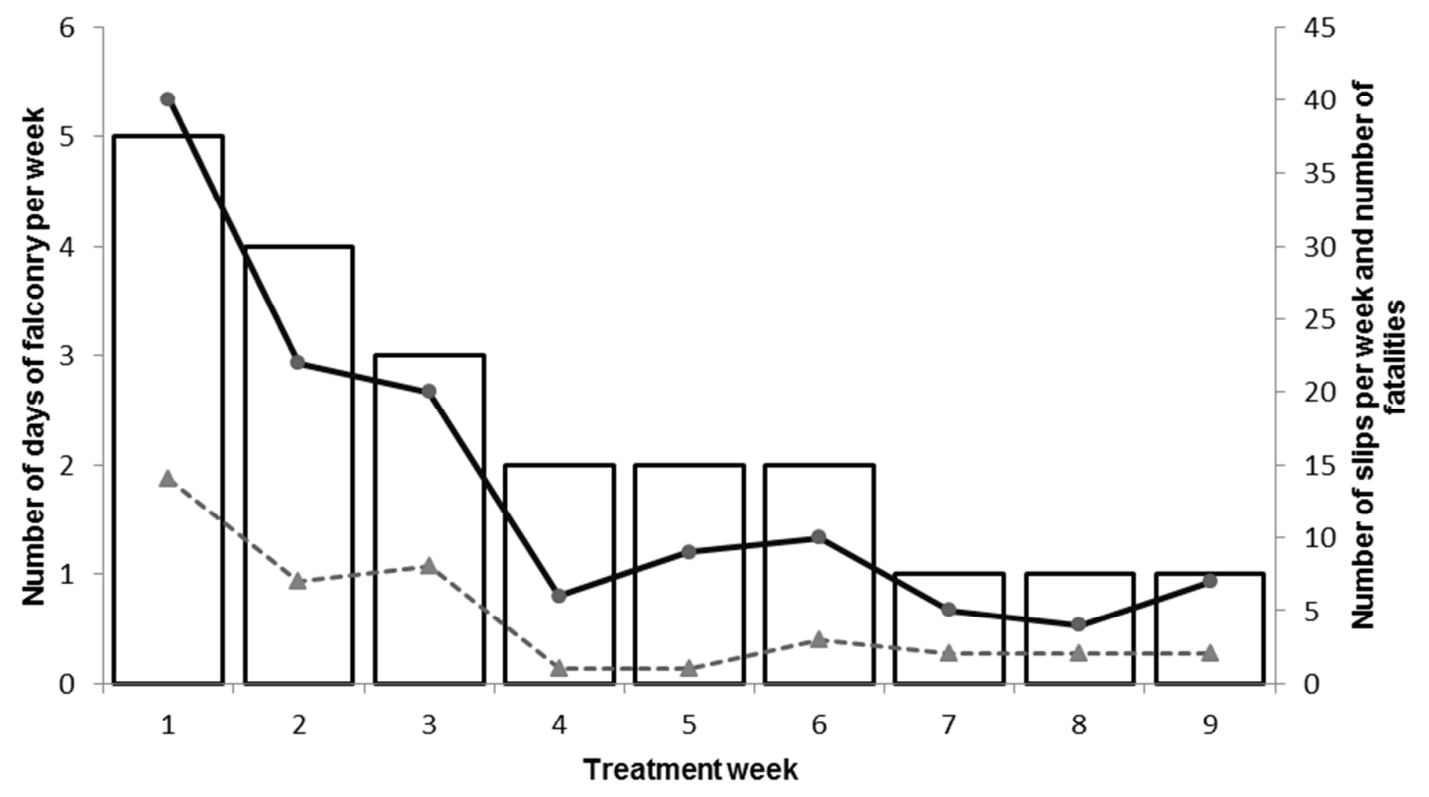


Figure. 2

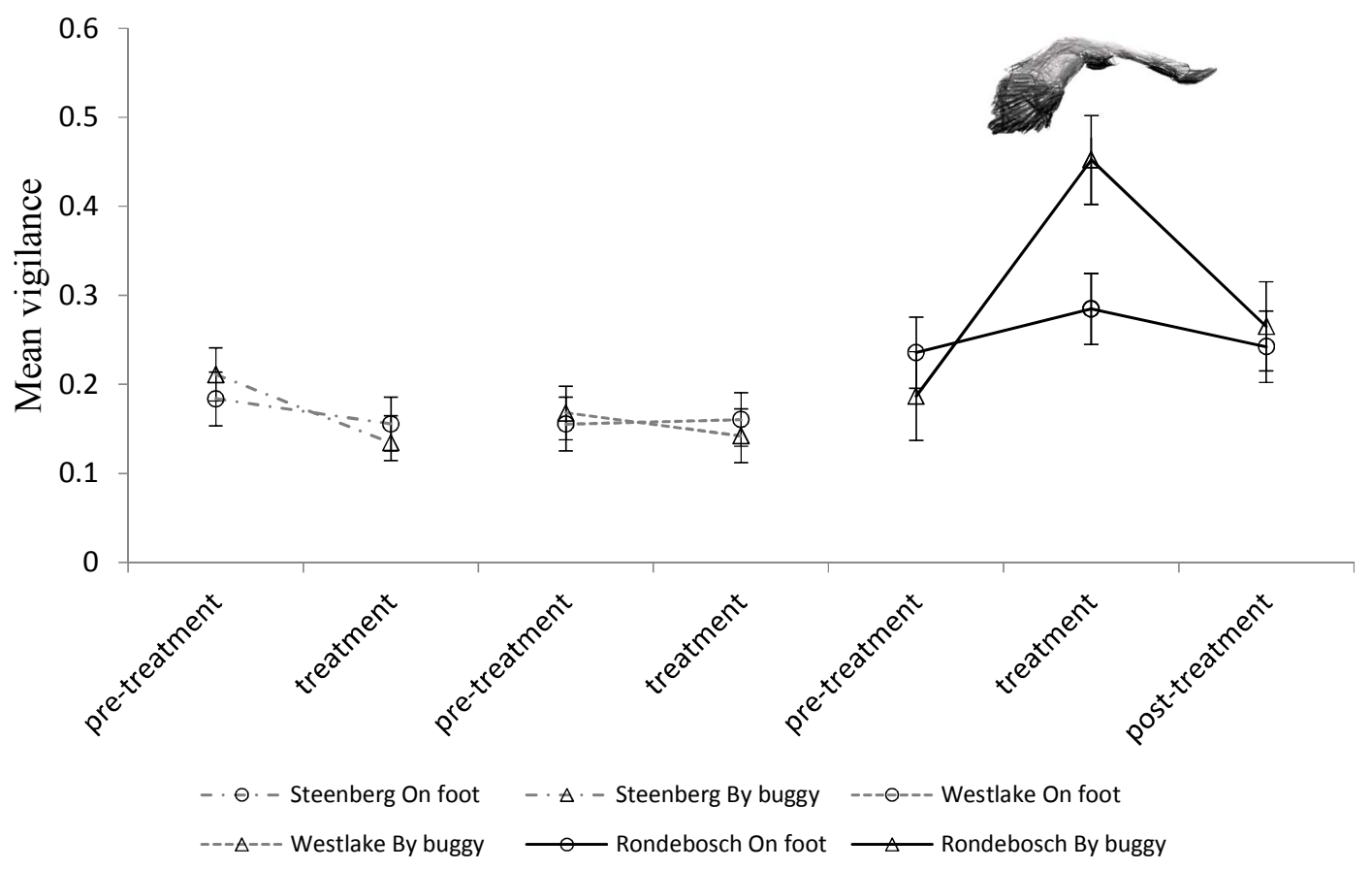


Page 31 of 31

Journal of Wildlife Management and Wildlife Monographs

Figure. 3



Monitoring period 
Figure. 4



